\title{
Assessment of impact of standing long-cassette radiographs on surgical planning for lumbar pathology: an international survey of spine surgeons
}

\author{
Dominic Maggio, MD, MBA, ${ }^{1}$ Tamir T. Ailon, MD, Justin S. Smith, MD, PhD, ${ }^{1}$ \\ Christopher I. Shaffrey, MD, ${ }^{1}$ Virginie Lafage, PhD, ${ }^{2}$ Frank Schwab, MD, ${ }^{2}$ Regis W. Haid Jr., MD, ${ }^{3}$ \\ Themistocles Protopsaltis, MD, ${ }^{2}$ Eric Klineberg, MD, ${ }^{4}$ Justin K. Scheer, BS, ${ }^{5}$ Shay Bess, MD, ${ }^{6}$ \\ Paul M. Arnold, MD, J Jens Chapman, MD, ${ }^{8}$ Michael G. Fehlings, MD, PhD, ${ }^{9}$ \\ Christopher Ames, MD, ${ }^{10}$ AOSpine North America, and the International Spine Study Group
}

${ }^{1}$ Department of Neurosurgery, University of Virginia Medical Center, Charlottesville, Virginia; ${ }^{2}$ Department of Orthopaedic Surgery, NYU Hospital for Joint Diseases, New York, New York; ${ }^{3}$ Atlanta Brain and Spine Care, Atlanta, Georgia; ${ }^{4}$ Department of Orthopaedic Surgery, University of California, Davis, Sacramento, California; ${ }^{5}$ Department of Neurosurgery, Northwestern University Feinberg School of Medicine, Chicago, Illinois; ${ }^{6}$ Department of Orthopaedic Surgery, Rocky Mountain Hospital for Children, Denver, Colorado; 'Department of Neurosurgery, University of Kansas Medical Center, Kansas City, Kansas; ${ }^{8}$ Department of Orthopaedic Surgery, University of Washington, Seattle, Washington; ' $D$ Division of Neurosurgery, University of Toronto, Ontario, Canada; and ${ }^{10}$ Department of Neurosurgery, University of California, San Francisco, California

OBJECT The associations among global spinal alignment, patient-reported disability, and surgical outcomes have increasingly gained attention. The assessment of global spinal alignment requires standing long-cassette anteroposterior and lateral radiographs; however, spine surgeons routinely rely only on short-segment imaging when evaluating seemingly isolated lumbar pathology. This may prohibit adequate surgical planning and may predispose surgeons to not recognize associated pathology in the thoracic spine and sagittal spinopelvic malalignment. The authors used a case-based survey questionnaire to evaluate if including long-cassette radiographs led to changes to respondents' operative plans as compared with their chosen plan when cases contained standard imaging of the involved lumbar spine only.

METHODS A case-based survey was distributed to AOSpine International members that consisted of 15 cases of lumbar spine pathology and lumbar imaging only. The same 15 cases were then shuffled and presented a second time with additional long-cassette radiographs. Each case required participants to select a single operative plan with 5 choices ranging from least to most extensive. The cases included 5 "control" cases with normal global spinal alignment and 10 "test" cases with significant sagittal and/or coronal malalignment. Mean scores were determined for each question with higher scores representing more invasive and/or extensive operative plans.

\footnotetext{
ABBREVIATIONS ASP = adjacent segment pathology; HRQOL = health-related quality of life; $\mathrm{PA}=$ posteroanterior; $\mathrm{PJF}=$ proximal junctional failure; $\mathrm{PJK}=$ proximal junctional kyphosis; PT = pelvic tilt; SVA = sagittal vertical axis; UIV = uppermost instrumented vertebra.

SUBMITTED August 13, 2014. ACCEPTED January 27, 2015.

INCLUDE WHEN CITING Published online July 31, 2015; DOI: 10.3171/2015.1.SPINE14833.

DISCLOSURE The International Spine Study Group (ISSG) is funded through research grants from DePuy Synthes and individual donations, and AOSpine North America receives funding through DePuy Synthes. Dr. Ames is a consultant for DePuy, Medtronic, and Stryker; owns stock in Baxano Surgical and Doctors Research Group; holds a patent with Fish \& Richardson, PC; and receives royalties from Aesculap and Biomet Spine. Dr. Smith is a consultant for Biomet and Nuvasive; has received clinical or research support from AOSpine NA and DePuy/ISSG for the study described; has received support from DePuy/ISSG for non-study-related clinical or research effort; and has received honoraria for teaching from Globus, DePuy, and Medtronic. Dr. Arnold is a consultant for Medtronic Sofamor Danek, Stryker Spine, and FzioMed; owns stock in Z-Plasty; and has received sponsored or reimbursed travel from AOSpine NA. Dr. Lafage owns stock in Nemaris Inc.; has received support from DePuy, SRS, NIH, and ISSG for non-study-related clinical or research effort; is a consultant for MSD and Medicrea; and has been a teacher/speaker for DePuy, K2M, NuVasive, and Nemaris Inc. Dr. Schwab owns stock in Nemaris Inc.; is a consultant for MSD, K2M, DePuy, and Medicrea; has received support from DePuy, MSD, and AO for non-study-related clinical or research effort; holds patents with MSD, Nemaris, K2M, and NuVasive; and has been a teacher/speaker for MSD, Nemaris Inc., and K2M. Dr. Bess is a consultant for K2 Medical, Allosource, and NuVasive; received clinical or research support from DePuy Synthes for the study described; has received support from Medtronic, K2 Medical, and Innovasis for non-study-related clinical or research effort. Dr.Klineberg has received grant and speaker fees from DePuy Synthes, a research grant and speakers fees from AOSpine, and a fellowship grant from OREF. Dr. Protopsaltis is a consultant for Medicrea, Biomet Spine, and Alphatec and has received support from Zimmer Spine for non-study-related clinical or research effort. Dr. Shaffrey is a consultant for Biomet, Globus, Medtronic, NuVasive, and Stryker; owns stock in NuVasive; and receives royalties from and holds patents with Biomet, Medtronic, and NuVasive.
} 
RESULTS Of 712 spine surgeons who started the survey, 316 (44\%) completed the entire series, including $68 \%$ of surgeons with spine fellowship training and representation from more than 40 countries. For test cases, but not for control cases, there were significantly higher average surgical invasiveness scores for cases presented with long-cassette radiographs (4.2) as compared with those cases with lumbar imaging only (3.4; $p=0.002)$. The addition of long-cassette radiographs resulted in $82.1 \%$ of respondents recommending instrumentation up to the thoracic spine, a $23.2 \%$ increase as compared with the same cases presented with lumbar imaging only $(p=0.008)$.

CONCLUSIONS This study demonstrates the importance of maintaining a low threshold for performing standing longcassette imaging when assessing seemingly isolated lumbar pathology. Such imaging is necessary for the assessment of spinopelvic and global spinal alignment, which can be important in operative planning. Deformity, particularly positive sagittal malalignment, may go undetected unless one maintains a high index of suspicion and obtains long-cassette radiographs. It is recommended that spine surgeons recognize the prevalence and importance of such deformity when contemplating operative intervention.

http://thejns.org/doi/abs/10.3171/2015.1.SPINE14833

KEY WORDS deformity; long-cassette imaging; lumbar; radiographs; spine alignment; surgery

$\mathrm{S}$ URGICAL planning to address seemingly isolated lumbar pathology may lead to suboptimal results if a patient's global spinal alignment is not taken into account. In recent years, there has been a greater appreciation of the interaction between different regions of the spine and the pelvis in producing harmonious global alignment. Malalignment in 1 region may result in compensatory changes in an adjacent (or even distant) region. This is particularly true in the setting of deformity surgery wherein correction of sagittal alignment can result in reciprocal changes to cephalad regions of the spine. For example, Lafage et al. ${ }^{28}$ reported a reciprocal increase in thoracic kyphosis within the unfused thoracic spine following lumbar pedicle subtraction osteotomy, which resulted in suboptimal postoperative alignment in 18 of 34 patients.

The relationship between the spine and the pelvis has also proven to be critical in predicting patient outcome. Increased pelvic tilt (PT), reflecting compensatory pelvic retroversion to correct for positive sagittal malalignment, strongly correlates with health-related quality of life (HRQOL) scores. ${ }^{29}$ Based on normative spinopelvic parameter data, corrective surgery should target a sagittal vertical axis (SVA) $<50 \mathrm{~mm}$ and a $\mathrm{PT}<20^{\circ}$. Furthermore, good postoperative HRQOL scores are correlated with a lumbar lordosis that is within approximately $10^{\circ}$ of the pelvic incidence. ${ }^{43}$

Postoperative positive SVA and coronal imbalance are major risk factors for the development of adjacent segment pathology (ASP) after lumbar or lumbosacral fusion. $., 11,21,26,30,37,41,46$ "Adjacent segment pathology" is a general term that refers to any abnormal process that develops in the mobile segment(s) adjacent to a spinal fusion, most commonly including disc degeneration ${ }^{20,34,36,38}$ but also including listhesis, hypertrophic facet joint arthritis, herniated nucleus pulposus, fracture of the rostral vertebral body, and spinal canal stenosis. ${ }^{2,5,9,14,27,31,41,50}$ ASP occurs after the use of lumbosacral instrumentation through a variety of mechanisms including increased facet and disc loading on the adjacent mobile segment. ${ }^{12,32}$ In patients with abnormal sagittal alignment after transpedicular posterolateral fusion, ASP usually results from increased loading of the posterior column and the posterior shear force at the proximal adjacent segment. ${ }^{45}$ The most common type of ASP in these patients is retrolisthesis..$^{26,30,41}$

In addition to SVA, spinopelvic parameters are important for predicting ASP and overall outcome in patients who undergo treatment with lumbosacral instrumentation. In a study by Kumar et al., the incidence of ASP after lumbar spine fusion was significantly lower in patients with normal SVA and normal sacral inclination in the immediate postoperative period, relative to that in patients with abnormalities in 1 or both of these parameters. ${ }^{26}$ Furthermore, HRQOL scores have been shown to be directly correlated with the degree of SVA and PT correction; ;,43 supine CT or MRI studies of the lumbosacral spine do not enable calculation of these important parameters and may therefore lead to a suboptimal operative plan if relied upon for these measurements.

Oftentimes, patients with identified lumbar spine pathology do not undergo standing long-cassette imaging to enable evaluation of global spinal alignment. Practitioners often make surgical decisions based solely on CT or MRI studies of the affected region. Scoliosis and sagittal plane deformity are common disorders that affect up to approximately $60 \%$ of the elderly population. ${ }^{42}$ We hypothesized that in cases with evidence of global spinal malalignment, practitioners would change their surgical plan when presented with standing long-cassette radiographs in addition to imaging studies of focal lumbar pathology, as compared with lumbar imaging alone. Conversely, we hypothesized that surgeons would not alter their operative plan when long-cassette radiographs demonstrated normal global spinal alignment.

\section{Methods}

Survey

This study was a case-based survey of AOSpine International members, a multinational group primarily composed of orthopedic and neurological spine surgeons. The survey included 5 demographic questions to determine the type and level of training and the spine practice characteristics for each participant. Data on country of practice were also collected. Participants were then presented with 15 sequential cases of lumbar spine pathology; each 
case included a brief clinical vignette and imaging of the lumbar spine, including CT myelogram or MR image and plain radiograph (Fig. 1). Following each case, participants were asked to select the single most-appropriate operative plan from 5 choices, ranging from least to most extensive (Table 1). Points were assigned for each response, with the least extensive option (choice $\mathrm{A}$ ) receiving 1 point and the most extensive option (choice $\mathrm{E}$ ) receiving 5 points; choices $\mathrm{B}, \mathrm{C}$, and $\mathrm{D}$ received 2,3 , and 4 points, respectively. Options D and E both entailed fusion up to the thoracic spine (to T-10 and T-3, respectively). The same 15 cases were then presented again in an alternate order, this time with the addition of standing long-cassette posteroanterior (PA) and lateral radiographs. The same question was then posed with the same 5 response options. Thus, each case was presented twice: first without and then with standing long-cassette radiographs. An invitation to participate in the survey was sent to the AOSpine International membership along with a link to complete the online survey. The survey did not include an explicit explanation of the purpose of the study in order to prevent bias in participant responses.

\section{Cases}

The 15 cases included 5 "control" and 10 "test" cases. Control cases were those for which the standing long-cassette radiographs demonstrated normal global alignment, whereas the test cases involved sagittal and/or coronal malalignment (Fig. 2). Abnormalities on test-case longcassette radiographs included positive sagittal malalignment, lumbar and/or thoracic scoliosis, flatback, proximal junction kyphosis, and thoracic hypo- or hyperkyphosis.

\section{Analysis}

Demographic information on survey participants was summarized. Mean scores for the initial 15 case-based survey questions (lumbar imaging only) were compared
TABLE 1. Surgical plan options

\begin{tabular}{cl}
\hline Option & \multicolumn{1}{c}{ Description } \\
\hline A & Noninstrumented decompression \\
\hline B & $\begin{array}{c}\text { Decompression \& short-segment (<5 levels) instrumented } \\
\text { arthrodesis }\end{array}$ \\
\hline C & $\begin{array}{c}\text { Decompression \& short-segment (<5 levels) instrumented } \\
\text { arthrodesis w/ 1 or more TLIF/PLIF }\end{array}$ \\
\hline D & $\begin{array}{c}\text { Decompression, T10-S1 or T10-ilium instrumented fusion } \pm \\
\text { interbody devices at L4-5 \& L5-S1, } \pm \text { osteotomies }\end{array}$ \\
\hline E & $\begin{array}{c}\text { Decompression, T3-S1 or T3-ilium instrumented fusion } \pm \\
\text { interbody devices at L4-5 \& L5-S1, } \pm \text { osteotomies }\end{array}$ \\
\hline
\end{tabular}

PLIF = posterior lumbar interbody fusion; TLIF = transforaminal lumbar interbody fusion.

with scores for the latter 15 questions (lumbar and longcassette imaging). This comparison was performed separately for control and test cases using a Student t-test for paired samples. The percentage of operative plans that employed thoracic instrumentation (survey responses D or E) was similarly assessed for control and test cases by comparing the initial to the latter 15 cases. The threshold for statistical significance was set at $\mathrm{p}<0.05$.

\section{Results}

\section{Survey Participants}

Of the 712 invited surgeons who started the survey, 316 (44\%) completed the entire series of 30 cases. The participants' practice locations represented more than 40 countries; the majority $(63 \%)$ of participants were from North America or Europe. Approximately two-thirds of participants had completed an orthopedic surgery residency, and one-third had completed a neurosurgery residency. Overall, $68 \%$ of participants had completed a spine fellowship. Surgical experience ranged from 1 to 50 years in practice

\section{2 y/o woman with mild low back pain and significant neurogenic claudication}
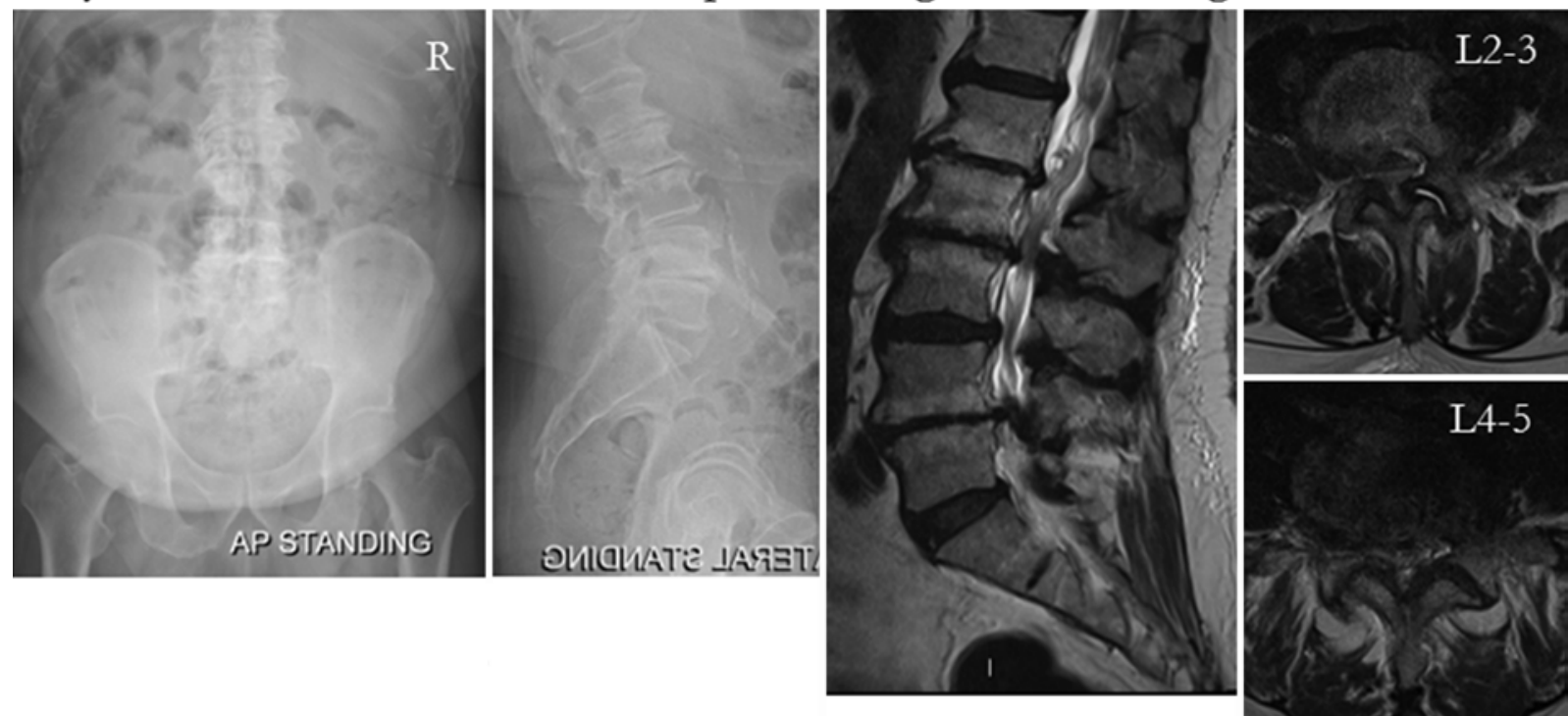

FIG. 1. A sample case that includes lumbar imaging and a brief clinical vignette. 

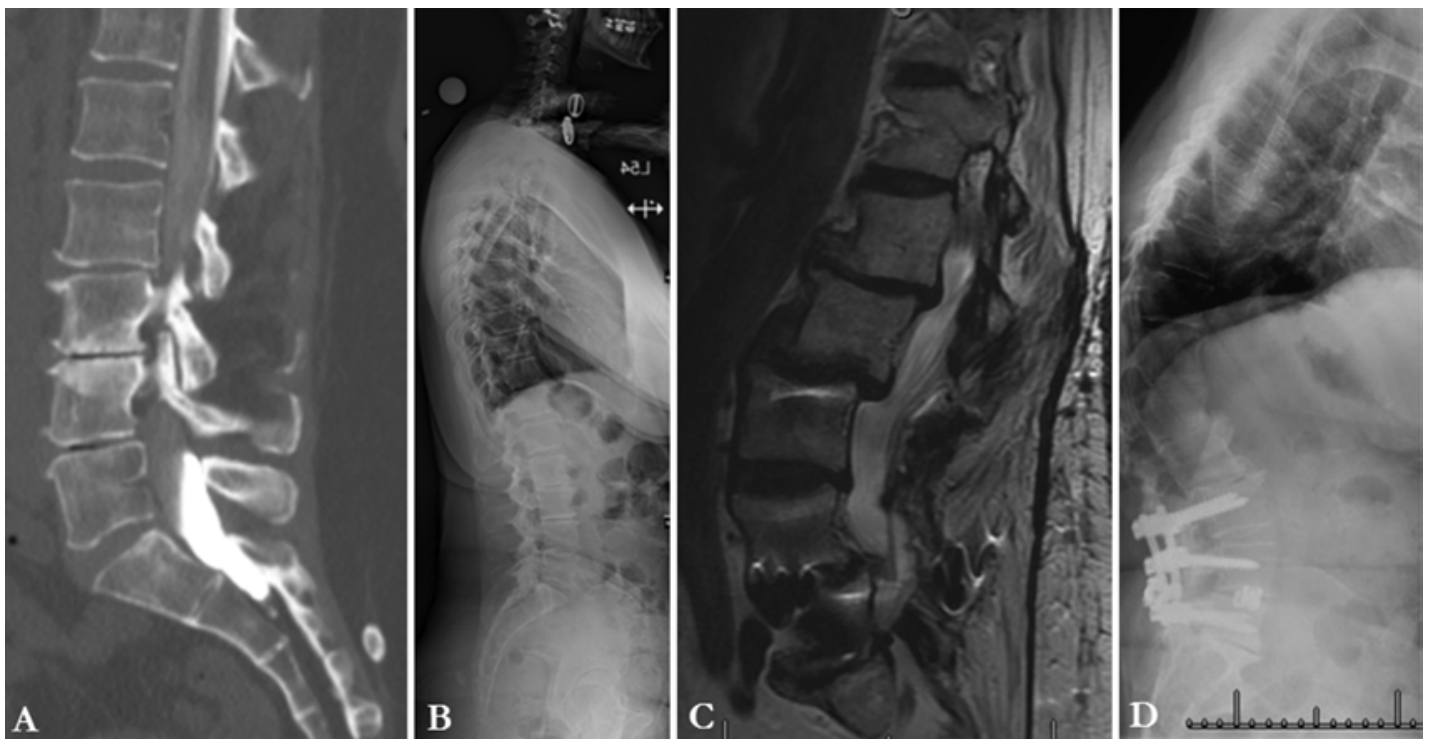

FIG. 2. Examples of control- and test-case imaging. A: Lumbar imaging for sample control case. B: Standing long-cassette radiograph of the same control case demonstrating normal global alignment. C: Lumbar imaging for sample test case. D: Standing long-cassette radiograph of the same test case demonstrating significantly positive SVA and thoracolumbar junction kyphosis.

with a mean of 13.6 years. Participants' practices included an average of $75 \%$ (range 5\%-100\%) spine cases and 119.8 fusions per year (range 10-600 fusions).

\section{Survey Responses}

The mean score was determined for each case-based survey question. Higher mean scores represent more extensive operative plans (Table 1). Tables 2 and 3 list mean scores and the percentage of participants who selected long instrumented fusion options (choices D and E) for control and test cases, respectively. For test cases, there was a significantly higher $(\mathrm{p}=0.002)$ mean response score for cases containing long-cassette radiographs (4.2) as compared with those cases containing lumbar imaging only (3.4). Conversely, there was no significant difference $(\mathrm{p}=0.28)$ among control cases (average response score of 2.1 for lumbar imaging only and 2.2 with standing longcassette imaging added). Figure 3 represents the change in the mean response score when long-cassette radiographs were added for individual control and test cases. Test cases had steeper slopes than control cases, representing a greater increase in response score with the addition of long-cassette radiographs.

Response options D and E both entailed an operative plan of long instrumented fusion that included the thoracic spine (Table 1). For control cases, the addition of standing long-cassette radiographs led to a mean increase in these responses from $4.9 \%$ to $9.0 \%$; however, this failed to reach significance $(\mathrm{p}=0.18)$. A significant increase was seen in the test cases, where presenting the same case with longcassette radiographs produced an increase in options $D$ and $\mathrm{E}$ from $58.9 \%$ to $82.1 \%$ (23.2\% increase; $\mathrm{p}=0.008$ ).

\section{Discussion}

Preferably, spine practitioners would have a relatively low threshold for obtaining anteroposterior and lateral standing long-cassette radiographs in patients with seemingly isolated lumbar pathology. We make this recommendation given the high prevalence of sagittal plane deformity in the adult population ${ }^{42}$ and its impact on the development of ASP in patients undergoing posterior lumbosacral fusion. ${ }^{9,21,26,30,37,41,46}$ ASP is an intriguing yet not fully understood occurrence, with a probable multifocal etiology; attempts to minimize ASP are important for minimizing the risk for revision surgery. ${ }^{9,39,41,49}$ In general, reoperations above previous lumbar spine fusions are undesirable, as success rates have been reported to decrease after each subsequent operative intervention. ${ }^{7,13,17}$ Mild-tomoderate sagittal plane deformity can be difficult to detect on physical exam alone since patients with a positive SVA can often maintain an upright posture and horizontal vi-

TABLE 2. Control cases: mean response scores and percent long instrumented fusion responses

\begin{tabular}{cccccc}
\hline & \multicolumn{2}{c}{ Mean Response Score $(95 \% \mathrm{Cl})$} & & \multicolumn{2}{c}{ Long Instrumented Fusion (\%) } \\
\cline { 2 - 3 } \cline { 5 - 6 } Case No. & Lumbar Imaging Only & Radiographs Added & & Lumbar Imaging Only & Radiographs Added \\
\hline 1 & $1.6(1.5-1.7)$ & $2.0(1.8-2.1)$ & & 2.0 & 14.8 \\
\hline 2 & $2.7(2.6-2.8)$ & $2.7(2.6-2.8)$ & & 7.1 & 8.6 \\
\hline 3 & $1.8(1.7-1.9)$ & $2.0(1.9-2.2)$ & & 2.4 & 9.3 \\
\hline 4 & $2.4(2.3-2.5)$ & $2.4(2.3-2.5)$ & & 3.6 & 3.7 \\
\hline 5 & $2.0(1.9-2.2)$ & $2.0(1.8-2.1)$ & & 9.7 & 9.0 \\
\hline
\end{tabular}


TABLE 3. Test cases: mean response scores and percent long instrumented fusion responses

\begin{tabular}{|c|c|c|c|c|}
\hline \multirow[t]{2}{*}{ Case No. } & \multicolumn{2}{|c|}{ Mean Response Score $(95 \% \mathrm{Cl})$} & \multicolumn{2}{|c|}{ Long Instrumented Fusion (\%) } \\
\hline & Lumbar Imaging Only & Radiographs Added & Lumbar Imaging Only & Radiographs Added \\
\hline 1 & $3.1(3.0-3.2)$ & $4.1(4.0-4.3)$ & 33.4 & 81.8 \\
\hline 2 & $2.2(2.1-2.3)$ & $4.4(4.2-4.5)$ & 4.6 & 78.7 \\
\hline 3 & $4.1(4.0-4.2)$ & $4.6(4.5-4.7)$ & 87.2 & 94.7 \\
\hline 4 & $3.9(3.7-4.0)$ & $4.3(4.2-4.5)$ & 77.9 & 83.9 \\
\hline 5 & $3.7(3.6-3.8)$ & $4.5(4.4-4.6)$ & 67.0 & 87.1 \\
\hline 6 & $3.8(3.7-3.9)$ & $4.2(4.1-4.3)$ & 81.9 & 90.6 \\
\hline 7 & $3.2(3.1-3.4)$ & $3.7(3.6-3.9)$ & 56.1 & 77.1 \\
\hline 8 & $3.5(3.3-3.6)$ & $4.4(4.3-4.6)$ & 62.9 & 84.0 \\
\hline 9 & $3.7(3.6-3.8)$ & $4.2(4.1-4.3)$ & 78.7 & 89.4 \\
\hline 10 & $3.2(3.1-3.3)$ & $3.5(3.4-3.6)$ & 39.7 & 53.7 \\
\hline
\end{tabular}

sual gaze through compensatory measures, such as pelvic retroversion, which helps bring the center of mass under the pelvis. ${ }^{30,40,52}$

Proximal junctional kyphosis (PJK) is a subset of ASP that attracts much attention in the spine deformity literature. PJK is defined as an increase in kyphosis between the caudal endplate of the uppermost instrumented vertebra (UIV) and the cephalad endplate of the vertebra 2 segments cranial to the UIV by $>10^{\circ}$ compared to preoperative imaging. ${ }^{8,10,23-25}$ A recent systematic review reported the development of PJK in $17 \%-39 \%$ of patients who underwent surgery for kyphosis and/or scoliosis. ${ }^{22}$ In contrast to many other forms of ASP, PJK has not been shown to consistently have a significant impact on HRQOL outcomes and reoperation rates ${ }^{10,19,22,24,33}$ or have a strong correlation with preoperative sagittal imbalance. ${ }^{22,24}$ However, a subset of PJK, known as "proximal junctional failure" (PJF), has recently been identified as a more severe form of PJK that is associated with an increased need for revision surgery. ${ }^{4,15,16,18,35,47,48,51}$

PJF is defined as a $>10^{\circ}$ change of kyphosis between the UIV and the vertebra 2 levels above the UIV (UIV+2), along with a fracture in the vertebral body of UIV or UIV+1 and/or a disruption of the posterior osseoligamentous complex and/or pullout of instrumentation at the UIV.4,15,16,18,35,47,48,51 Even though both PJK and PJF are defined, at least partly, by an increased proximal kyphosis, PJF is thought to represent an entity distinct from PJK with differing pathology and risk factors. Specifically, PJF appears to result from an acute event rather than from a recurrent deformity ${ }^{15,48}$ and has been shown to have a strong association with preoperative spinopelvic mismatch, increased SVA, and increased thoracic kyphosis. ${ }^{15,48,51}$ As noted previously, global sagittal alignment is important to evaluate preoperatively and can only be done with the use of long-cassette radiographs.

A recent review characterized the relationship of cervical sagittal alignment to segmental alignment of the thoracic and lumbar spine, global sagittal alignment, and spinopelvic alignment. ${ }^{1}$ The authors demonstrated that cervical lordosis may adapt to changes in other spinal segments to keep the head over the pelvis. Conversely, prima-
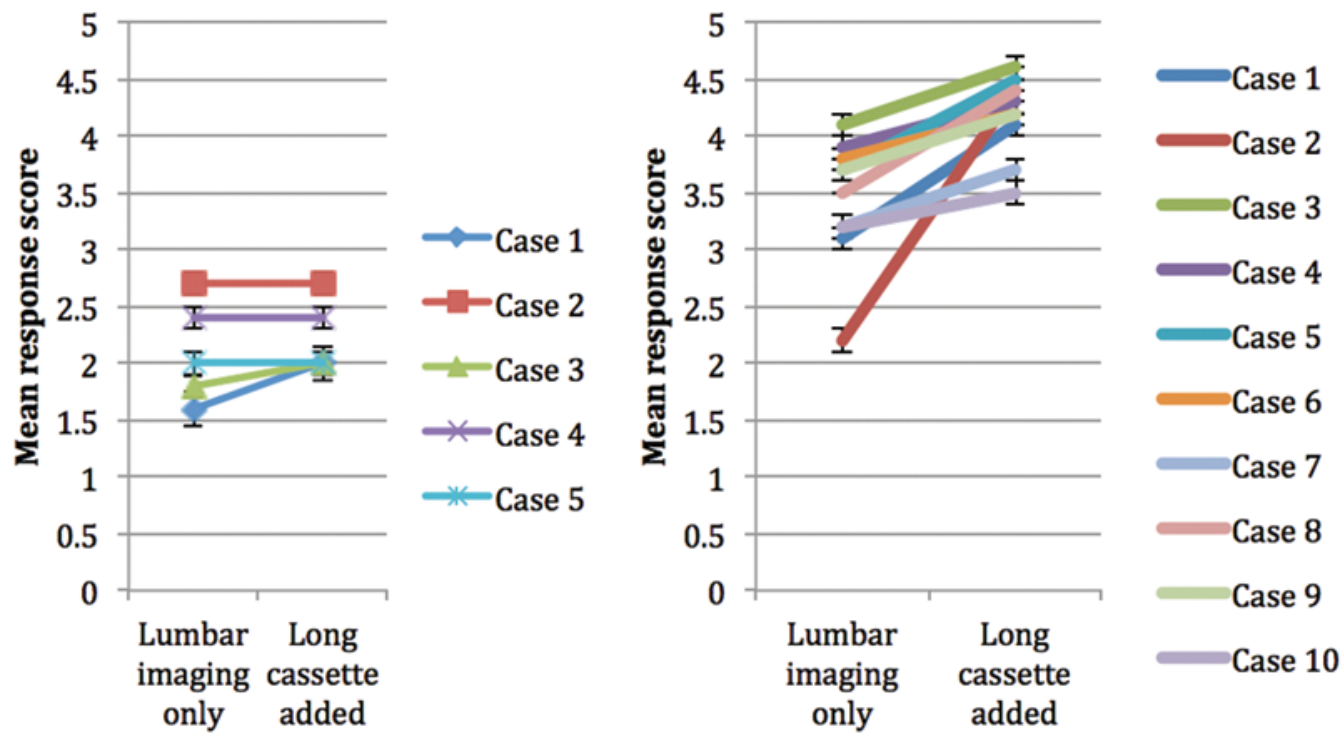

FIG. 3. Change in mean response score with the addition of long-cassette radiographs. An increased slope of the line corresponds to a greater increase in the mean response score. Left: Control cases. Right: Test cases. Figure is available in color online only. 
ry cervical kyphosis may result in compensatory hyperlordosis of the lumbar spine in conjunction with increased PT to maintain horizontal gaze. The complex and interdependent relationships between spinal segments and the pelvis and the resultant global alignment cannot be appreciated without obtaining standing long-cassette radiographs.

In our case-based survey, practitioners changed their operative plans when given long-cassette radiographs in addition to brief clinical presentations and lumbosacral imaging. They opted to use more extensive instrumentation in patients with positive SVA and/or scoliosis, presumably with a view to restoring coronal and sagittal alignment. This finding is in line with current literature highlighting the importance of restoring spinal alignment to minimize loading of unfused motion segments and thus reducing the incidence of ASP and PJF, 6,9,21,26,30,37,41,44,46 or minimizing exacerbation of a preexisting deformity. In addition, the restoration of spinal alignment, in particular the correction of positive sagittal malalignment, has been shown to be important in maximizing HRQOL and minimizing postoperative pain and disability. $32,37,50$

One strength of this study is its relatively large number of participants in a highly specialized field, many of whom had fellowship training. The geographic scope of the participants includes orthopedic and neurological surgeons from 40 different countries, with more than onethird of participants from outside of North America and Europe. However, the $44 \%$ survey completion rate constitutes a potential limitation of the study. It was not possible to determine why surgeons failed to complete the survey and if there was a differential loss of participants who would have otherwise recommended more or less extensive operative plans, which could have biased the results. Respondents had predominantly completed orthopedic residency (two-thirds) and the majority had fellowship training. Thus, the results of this study may not be fully generalizable to the sizable group of neurosurgeons who provide spine care, often without fellowship training. A further limitation is the ordinal nature of the outcome variable. Responses were assigned points (between 1 and 5) based on the level of extensiveness of the recommended surgical plan; however, the relative difference between 2 choices was not necessarily equivalent. For example, the difference between noninstrumented decompression (1 point) and short-segment instrumented fusion ( 2 points) is not precisely equal to the difference between T10-S1 fusion (4 points) and T3-S1 fusion (5 points). Unfortunately, no validated, linear scale that could be directly applied to the survey responses exists. The simplified scoring system employed in this study facilitated comparison of responses before and after the addition of long-cassette radiographs. Furthermore, including the dichotomous outcome variable of long instrumented fusion to the thoracic spine, not subject to the above concerns, supports the overall finding of increased extensiveness of the surgical plan after the addition of long-cassette radiographs.

Because of the survey format, participants did not have the option to obtain additional imaging during the evaluation of the first 15 cases. They were required to record a surgical plan when they might have otherwise obtained more extensive imaging (including long-cassette radiographs) prior to developing a plan. We attempted to minimize this factor by only including cases that were not necessarily suggestive of global imbalance on the lumbaronly imaging. This helped emphasize that coronal- and sagittal-plane deformity can occur in patients with what may appear to be normal lumbar spine alignment.

Although standing long-cassette radiographs can provide valuable information, we do not necessarily suggest that they should be obtained for every patient with possible lumbar pathology or even for all cases in which surgical intervention is being considered. Patient history and physical examination remain the cornerstones for evaluating a patient to determine the appropriate selection of imaging studies. It is important to recognize, however, that a physical exam may fail to reveal a substantial deformity, for example, when a high degree of pelvic retroversion compensates for sagittal malalignment. It is important to balance the potential benefits of appreciating global alignment with the potential risks of radiation exposure from the imaging as well as the added costs. Notably, newer technologies, such as the EOS imaging system, enable full-body (head-to-toe) imaging at a fraction of the radiation exposure of traditional systems and may lower the threshold for obtaining full-length images. Additional important structural spinal variables to consider include standing dynamic motion radiographs and a comprehensive physical examination to ensure the integrity of major lower-extremity joint function and trunk and torso musculature function.

While the findings of the present study argue for including long-cassette imaging in the algorithm for evaluating patients with lumbar pathology, future studies are required to determine the impact of longer constructs on patient outcome. Surgeons are commonly faced with patients who have focal lumbar pathology in the setting of some degree of spinal imbalance. Whether to address the presumed symptomatic pathology in isolation or as a component of a more extensive correction of malalignment is an important question that is not addressed by the immediate study. The present study, however, does underscore the potential impact of a more comprehensive full-length, weight-bearing radiographic study of the spinal column on the surgical planning for patients indicated for lumbar fusion surgery. Hopefully this insight will help increase the attention of spine surgeons on the role of spinal alignment and restoration during reconstructive surgery.

\section{Conclusions}

The present study adds to the growing body of evidence that supports the importance of long-cassette imaging on the choice of surgical plan for seemingly isolated lumbar pathology. In cases where global malalignment was present, the addition of long-cassette radiographs clearly influenced surgical decision making. Sagittal plane deformity can go undetected unless a relatively high index of suspicion is present. Failure to account for spinal deformity in this patient population may lead to a cascade of negative surgical outcomes. It is important for the spine provider to recognize the prevalence and effect of spinal deformity when contemplating operative intervention. 


\section{Acknowledgment}

We wish to acknowledge the skill and efforts of Ms. Chi Lamb from AOSpine North America in creating, distributing, and tabulating the on-line survey.

\section{References}

1. Ames CP, Blondel B, Scheer JK, Schwab FJ, Le Huec JC, Massicotte EM, et al: Cervical radiographical alignment: comprehensive assessment techniques and potential importance in cervical myelopathy. Spine (Phila Pa 1976) 38 (22 Suppl 1):S149-S160, 2013

2. Axelsson P, Johnsson R, Strömqvist B, Arvidsson M, Herrlin $\mathrm{K}$ : Posterolateral lumbar fusion. Outcome of 71 consecutive operations after 4 (2-7) years. Acta Orthop Scand 65:309314, 1994

3. Blondel B, Schwab F, Ungar B, Smith J, Bridwell K, Glassman S, et al: Impact of magnitude and percentage of global sagittal plane correction on health-related quality of life at 2-years follow-up. Neurosurgery 71:341-348, 2012

4. Bridwell KH, Baldus C, Berven S, Edwards C II, Glassman $\mathrm{S}$, Hamill C, et al: Changes in radiographic and clinical outcomes with primary treatment adult spinal deformity surgeries from two years to three- to five-years follow-up. Spine (Phila Pa 1976) 35:1849-1854, 2010

5. Brodsky AE: Post-laminectomy and post-fusion stenosis of the lumbar spine. Clin Orthop Relat Res (115):130-139, 1976

6. Callaghan JP, Gunning JL, McGill SM: The relationship between lumbar spine load and muscle activity during extensor exercises. Phys Ther 78:8-18, 1998

7. Christensen FB, Thomsen K, Eiskjaer SP, Gelinick J, Bünger $\mathrm{CE}$ : Functional outcome after posterolateral spinal fusion using pedicle screws: comparison between primary and salvage procedure. Eur Spine J 7:321-327, 1998

8. Denis F, Sun EC, Winter RB: Incidence and risk factors for proximal and distal junctional kyphosis following surgical treatment for Scheuermann kyphosis: minimum five-year follow-up. Spine (Phila Pa 1976) 34:E729-E734, 2009

9. Etebar S, Cahill DW: Risk factors for adjacent-segment failure following lumbar fixation with rigid instrumentation for degenerative instability. J Neurosurg 90 (2 Suppl):163-169, 1999

10. Glattes RC, Bridwell KH, Lenke LG, Kim YJ, Rinella A, Edwards C II: Proximal junctional kyphosis in adult spinal deformity following long instrumented posterior spinal fusion: incidence, outcomes, and risk factor analysis. Spine (Phila Pa 1976) 30:1643-1649, 2005

11. Ha KY, Kim YH, Ahn JH: Is it real adjacent segment pathology by stress concentration after limited fusion in degenerative lumbar scoliosis? Spine (Phila Pa 1976) 39:1059-1066, 2014

12. Ha KY, Schendel MJ, Lewis JL, Ogilvie JW: Effect of immobilization and configuration on lumbar adjacent-segment biomechanics. J Spinal Disord 6:99-105, 1993

13. Hadjipavlou A, Enker P, Dupuis P, Katzman S, Silver J: The causes of failure of lumbar transpedicular spinal instrumentation and fusion: a prospective study. Int Orthop 20:35-42, 1996

14. Hambly MF, Wiltse LL, Raghavan N, Schneiderman G, Koenig C: The transition zone above a lumbosacral fusion. Spine (Phila Pa 1976) 23:1785-1792, 1998

15. Hart RA, McCarthy I, Ames CP, Shaffrey CI, Hamilton DK, Hostin R: Proximal junctional kyphosis and proximal junctional failure. Neurosurg Clin N Am 24:213-218, 2013

16. Hart RA, Prendergast MA, Roberts WG, Nesbit GM, Barnwell SL: Proximal junctional acute collapse cranial to multilevel lumbar fusion: a cost analysis of prophylactic vertebral augmentation. Spine (Phila Pa 1976) J 8:875-881, 2008
17. Herno A, Airaksinen O, Saari T, Sihvonen T: Surgical results of lumbar spinal stenosis. A comparison of patients with or without previous back surgery. Spine (Phila Pa 1976) 20:964-969, 1995

18. Hostin R, McCarthy I, O’Brien M, Bess S, Line B, BoachieAdjei $\mathrm{O}$, et al: Incidence, mode, and location of acute proximal junctional failures following surgical treatment for adult spinal deformity. Spine (Phila Pa 1976), 2012

19. Hyun SJ, Rhim SC: Clinical outcomes and complications after pedicle subtraction osteotomy for fixed sagittal imbalance patients: a long-term follow-up data. J Korean Neurosurg Soc 47:95-101, 2010

20. Ishihara H, Osada R, Kanamori M, Kawaguchi Y, Ohmori K, Kimura T, et al: Minimum 10-year follow-up study of anterior lumbar interbody fusion for isthmic spondylolisthesis. J Spinal Disord 14:91-99, 2001

21. Keene JS, Lash EG, Kling TF Jr: Undetected posttraumatic instability of "stable" thoracolumbar fractures. J Orthop Trauma 2:202-211, 1988

22. Kim HJ, Lenke LG, Shaffrey CI, Van Alstyne EM, Skelly AC: Proximal junctional kyphosis as a distinct form of adjacent segment pathology after spinal deformity surgery: a systematic review. Spine (Phila Pa 1976) 37 (22 Suppl):S144S164, 2012

23. Kim HJ, Yagi M, Nyugen J, Cunningham ME, Boachie-Adjei $\mathrm{O}$ : Combined anterior-posterior surgery is the most important risk factor for developing proximal junctional kyphosis in idiopathic scoliosis. Clin Orthop Relat Res 470:1633-1639, 2012

24. Kim YJ, Bridwell KH, Lenke LG, Glattes CR, Rhim S, Cheh G: Proximal junctional kyphosis in adult spinal deformity after segmental posterior spinal instrumentation and fusion: minimum five-year follow-up. Spine (Phila Pa 1976) 33:2179-2184, 2008

25. Kim YJ, Lenke LG, Bridwell KH, Kim J, Cho SK, Cheh G, et al: Proximal junctional kyphosis in adolescent idiopathic scoliosis after 3 different types of posterior segmental spinal instrumentation and fusions: incidence and risk factor analysis of 410 cases. Spine (Phila Pa 1976) 32:2731-2738, 2007

26. Kumar MN, Baklanov A, Chopin D: Correlation between sagittal plane changes and adjacent segment degeneration following lumbar spine fusion. Eur Spine J 10:314-319, 2001

27. Kumar MN, Jacquot F, Hall H: Long-term follow-up of functional outcomes and radiographic changes at adjacent levels following lumbar spine fusion for degenerative disc disease. Eur Spine J 10:309-313, 2001

28. Lafage V, Ames C, Schwab F, Klineberg E, Akbarnia B, Smith J, et al: Changes in thoracic kyphosis negatively impact sagittal alignment after lumbar pedicle subtraction osteotomy: a comprehensive radiographic analysis. Spine (Phila Pa 1976) 37:E180-E187, 2012

29. Lafage V, Schwab F, Patel A, Hawkinson N, Farcy JP: Pelvic tilt and truncal inclination: two key radiographic parameters in the setting of adults with spinal deformity. Spine (Phila Pa 1976) 34:E599-E606, 2009

30. Lazennec JY, Ramaré S, Arafati N, Laudet CG, Gorin M, Roger B, et al: Sagittal alignment in lumbosacral fusion: relations between radiological parameters and pain. Eur Spine J 9:47-55, 2000

31. Lee CK: Accelerated degeneration of the segment adjacent to a lumbar fusion. Spine (Phila Pa 1976) 13:375-377, 1988

32. Lee CK, Langrana NA: Lumbosacral spinal fusion. A biomechanical study. Spine (Phila Pa 1976) 9:574-581, 1984

33. Lee GA, Betz RR, Clements DH III, Huss GK: Proximal kyphosis after posterior spinal fusion in patients with idiopathic scoliosis. Spine (Phila Pa 1976) 24:795-799, 1999

34. Leong JC, Chun SY, Grange WJ, Fang D: Long-term results of lumbar intervertebral disc prolapse. Spine (Phila Pa 1976) 8:793-799, 1983 
35. Lewis SJ, Abbas H, Chua S, Bacon S, Bronstein Y, Goldstein S, et al: Upper instrumented vertebral fractures in long lumbar fusions: what are the associated risk factors? Spine (Phila Pa 1976) 37:1407-1414, 2012

36. Miyakoshi N, Abe E, Shimada Y, Okuyama K, Suzuki T, Sato K: Outcome of one-level posterior lumbar interbody fusion for spondylolisthesis and postoperative intervertebral disc degeneration adjacent to the fusion. Spine (Phila Pa 1976) 25:1837-1842, 2000

37. Park P, Garton HJ, Gala VC, Hoff JT, McGillicuddy JE: Adjacent segment disease after lumbar or lumbosacral fusion: review of the literature. Spine (Phila Pa 1976) 29:19381944,2004

38. Penta M, Sandhu A, Fraser RD: Magnetic resonance imaging assessment of disc degeneration 10 years after anterior lumbar interbody fusion. Spine (Phila Pa 1976) 20:743-747, 1995

39. Rahm MD, Hall BB: Adjacent-segment degeneration after lumbar fusion with instrumentation: a retrospective study. $\mathbf{J}$ Spinal Disord 9:392-400, 1996

40. Sarwahi V, Boachie-Adjei O, Backus SI, Taira G: Characterization of gait function in patients with postsurgical sagittal (flatback) deformity: a prospective study of 21 patients. Spine (Phila Pa 1976) 27:2328-2337, 2002

41. Schlegel JD, Smith JA, Schleusener RL: Lumbar motion segment pathology adjacent to thoracolumbar, lumbar, and lumbosacral fusions. Spine (Phila Pa 1976) 21:970-981, 1996

42. Schwab F, Dubey A, Gamez L, El Fegoun AB, Hwang K, Pagala M, et al: Adult scoliosis: prevalence, SF-36, and nutritional parameters in an elderly volunteer population. Spine (Phila Pa 1976) 30:1082-1085, 2005

43. Schwab F, Patel A, Ungar B, Farcy JP, Lafage V: Adult spinal deformity-postoperative standing imbalance: how much can you tolerate? An overview of key parameters in assessing alignment and planning corrective surgery. Spine (Phila Pa 1976) 35:2224-2231, 2010

44. Swinkels A, Dolan P: Regional assessment of joint position sense in the spine. Spine (Phila Pa 1976) 23:590-597, 1998

45. Umehara S, Zindrick MR, Patwardhan AG, Havey RM, Vrbos LA, Knight GW, et al: The biomechanical effect of postoperative hypolordosis in instrumented lumbar fusion on instrumented and adjacent spinal segments. Spine (Phila Pa 1976) 25:1617-1624, 2000

46. Vaccaro AR, Silber JS: Post-traumatic spinal deformity. Spine (Phila Pa 1976) 26 (24 Suppl):S111-S118, 2001
47. Venu V, Vertinsky AT, Malfair D, Chew JB, Shewchuk J, Heran MK, et al: Plain radiograph assessment of spinal hardware. Semin Musculoskelet Radiol 15:151-162, 2011

48. Watanabe K, Lenke LG, Bridwell KH, Kim YJ, Koester L, Hensley M: Proximal junctional vertebral fracture in adults after spinal deformity surgery using pedicle screw constructs: analysis of morphological features. Spine (Phila Pa 1976) 35:138-145, 2010

49. Whitecloud TS III, Davis JM, Olive PM: Operative treatment of the degenerated segment adjacent to a lumbar fusion. Spine (Phila Pa 1976) 19:531-536, 1994

50. Wimmer C, Gluch H, Krismer M, Ogon M, Jesenko R: APtranslation in the proximal disc adjacent to lumbar spine fusion. A retrospective comparison of mono- and polysegmental fusion in 120 patients. Acta Orthop Scand 68:269-272, 1997

51. Yagi M, Akilah KB, Boachie-Adjei O: Incidence, risk factors and classification of proximal junctional kyphosis: surgical outcomes review of adult idiopathic scoliosis. Spine (Phila Pa 1976) 36:E60-E68, 2011

52. Yoshimoto H, Sato S, Masuda T, Kanno T, Shundo M, Hyakumachi T, et al: Spinopelvic alignment in patients with osteoarthrosis of the hip: a radiographic comparison to patients with low back pain. Spine (Phila Pa 1976) 30:1650-1657, 2005

\section{Author Contributions}

Conception and design: Smith, Shaffrey, Lafage, Schwab, Haid, Protopsaltis, Klineberg, Bess, Arnold, Chapman, Fehlings, Ames. Acquisition of data: Smith. Analysis and interpretation of data: Smith, Maggio, Ailon, Shaffrey. Drafting the article: Smith, Maggio, Ailon. Critically revising the article: Smith, Maggio, Ailon, Shaffrey, Lafage, Schwab, Haid, Klineberg, Bess, Arnold, Chapman, Fehlings, Ames. Reviewed submitted version of manuscript: all authors. Approved the final version of the manuscript on behalf of all authors: Smith. Statistical analysis: Smith, Ailon. Administrative/technical/material support: Smith, Shaffrey. Study supervision: Smith, Shaffrey.

\section{Correspondence}

Justin S. Smith, Department of Neurosurgery, University of Virginia Health Sciences Center, Box 800212, Charlottesville, VA 22908. email: jss7f@virginia.edu. 